\title{
Escola Pública vítima de depredação e foco de violência: análise ética como mediação entre os agentes institucionais envolvidos
}

\section{Resumo}

Intervenção institucional em escola municipal na cidade de São Paulo, foco de violência e depredação, visando agenciar a participação do maior número de pessoas envolvidas direta ou indiretamente com a escola, com base nos conceitos teóricos desenvolvidos pelos pensadores Gilles Deleuze e Félix Guattari. Durante o período em que foi possível uma maior participação das pessoas no cotidiano escolar, estimulada por reuniões de grupos representativos da população institucional envolvida (pais, alunos, professores, funcionários, direção), verificou-se diminuição dos problemas de violência e depredação, bem como um maior zelo por parte de todos no que se refere aos cuidados com o patrimônio público, visto que todos tinham espaço para discutir e reivindicar seus interesses relativos à escola, de modo geral, discrepantes.

\section{Abstract}

This study relates a institutional intervention in a São Paulo City county public school, with a high rate of violence and depredation, for getting the participation of everybody directy ou indirecty involved in the school matters. The Gilles Deleuze and Felix Gattari's framework theorical concepts is used for analising and discussing the problem by community representative groups in school meetings. The issues demonstrate that violence and depredation decrease while these meetings are happening and at the same time the care with the public patrimony increases, since all of them could discuss and claim their interests about school, although with discrepancies.

\section{Introdução}

O presente trabalho foi realizado em uma escola municipal de ensino fundamental da cidade de São Paulo, situada em um bairro periférico, selecionada para esta pesquisa por sua situação de constantes depredações e rotineira violência, bem como pela disposição de sua direção em implementar mudanças de caráter participativo.

$\mathrm{Na}$ ocasião, os diversos agentes institucionais - professores, alunos, funcionários, pais de alunos, direção da escola - identificavam, uns nos outros, as causas dos problemas, em acusações mútuas e improdutivas.

Em tais situações, os atuais ideários acerca da gestão escolar pregam a necessidade da participação de tais agentes na resolução de problemas comuns a todos. Essa ênfase na importância da participação teve origem fortemente no início da década de 90 (ver, por exemplo, CAMPOS, 1991 e 1994; PARO, 1992a e 1992b; PIMENTA, 1993; RIVAS, 1991), sendo considerada relevante até os dias de hoje.

No entanto, as dificuldades em se implantar uma gestão verdadeiramente participativa, além da mera representação (Cf. RIVAS, 1991), tem sido o grande obstáculo para tornar a instituição pública acessível à população interessada.

A questão é que conhecemos experiências relatadas, segundo as quais, a participação pode agenciar mudanças positivas, não significando, todavia, em si, melhorias imediatas, mas um espaço onde poderia ocorrer a crise, com os impasses, os desentendimentos antes camuflados

* Doutorando em Educação - USP/SP. Mestre em Educação: História e Filosofia da Educação - PUC/SP. Pedagogo e Psicólogo - Unesp - Assis/SP. Professor das Faculdades Integradas "Campos Salles".

19 Este texto consiste em versão revista e ampliada de trabalho apresentado na 51ª Reunião da Sociedade Brasileira para o Progresso da Ciência, realizada em Porto Alegre-RS, em julho de 1999. 
por uma aparente "ordem natural" das coisas. (ver PARO, 1995).

Neste estudo, buscamos contribuir com as discussões sobre as dificuldades da participação de pessoas envolvidas com o cotidiano escolar na administração dos problemas da escola, relatando sucessos e fracassos ocorridos durante uma experiência de gestão participativa escolar que durou aproximadamente seis meses e que visava a melhoria da qualidade do ensino, bem como do ambiente institucional, diminuindo os conflitos ou tornando-os mais produtivos, sendo que tal experiência foi interrompida com a troca dos diretores da instituição.

Assim, podemos dizer que foram os objetivos deste trabalho de campo, verificar se havia a participação do maior número de pessoas envolvidas direta ou indiretamente com a escola, para buscar saídas coletivas para os problemas de depredação e violência escolar, bem como outros comuns à rotina da instituição, redundando, de alguma forma, na melhoria de tais condições.

A dificuldade em se encontrar instrumentos que permitissem uma análise institucional do que acontece com os agentes institucionais durante $\mathrm{o}$ processo, gerou em nós a necessidade de uma pesquisa que relatasse acontecimentos comuns a mudanças gestionárias de cunho participativo, bem como conceitos teóricos que nos permitissem tais análises de modo mais profundo.

\section{A escola e o conhecimento: ética e moral}

Ao pensar sobre os avanços da tecnologia e as modificações violentas e irreversíveis que tal desenvolvimento tẹm determinado ao cenário social, do ponto de vista do educador, pensamos em instrumentos para possibilitar o acesso do maior número de pessoas a esses avanços. Tratase da democratização dos bens produzidos pela humanidade, que, no sistema capitalista de produção, consideramos resultante do trabalho da maioria da população economicamente ativa, exatamente a que menos usufrui do progresso, efeito direto da exploração de seu trabalho.

Entendemos, portanto, democracia, como acesso de todos à vida, ao gozo da vida e, evidentemente, à gestão da mesma, ou como nos termos de $\mathrm{BOBBIO}$, ou seja, de que "todos [possam] decidir a respeito de tudo." (BOBBIO, 1986:34).

Temos o conhecimento, seja ele oriundo de princípios básicos de Física, fundamentos epistemológicos da Filosofia, computação, dentre tantos outros possíveis. Temos um professor. Finalmente, alunos. Temos ainda todos os funcionários da escola e todas as pessoas envolvidas direta ou indiretamente com essa escola.

Se relevarmos que o objeto da escola não é a aula, mas o aluno - um objeto muito especial por ser também sujeito - que precisa ser transformado desde que entra até o momento que sai da escola (Cf. PARO, 1997), pressupomos um corpo de conhecimentos adequados a essa finalidade. Consideramos esse conhecimento, enquanto instrumento, como um valor: algo que defendemos e que acreditamos necessário. Ele ganha, então, uma conotação moral: são modelos, normas, regras, teorias etc. importantes para a vida em sociedade. São, portanto, conhecimentos preestabelecidos, considerados meios importantes para a formação de um cidadão, a finalidade de todo esse processo: é a mediação necessária para a vida em sociedade, para a compreensão crítica de seus códigos, suas regras.

A socialização se dá exatamente pela aprendizagem desses códigos. Não é isso, em última instância, a própria educação? Isso, seja na visão durkheimiana que define a educação como a ação das gerações mais velhas sobre as mais novas ou, mesmo na visão freudiana, na qual a criança, ainda bebê, abandona seu estado esquizóide quando reconhece a mãe, uma mãe que não é mais extensão de si, mas um outro; um outro que não lhe pertence, pertencendo ao pai, à lei, que a partir de agora ditará as regras de como obter prazer, não a qualquer hora e lugar, mas a partir de normas, de leis, de regras de conduta.

Quando pensamos em currículos adequados, 
estamos considerando conteúdos que devem ser aprendidos, preestabelecidos. Educação, sob esse prisma, é basicamente moralização; adequação à normas, sejam elas de interesses políticos de esquerda ou direita. É claro que a educação escolar pressupõe formar uma pessoa que saiba escolher, que tenha capacidade de reflexão. Essa capacidade, todavia, enquanto um valor que defendemos para a formação de um educador, é também do domínio da moral (veremos mais adiante as terríveis conseqüências desta última máxima).

No entanto, enquanto educadores, temos defendido a postura ética do educador, a formação ética do cidadão e, ao mesmo tempo, falar em moral nos remete a pensar em moralismo, em imposição da moral - valores - pela força. A fim de evitar confusões, faremos uma pequena pausa para propor uma distinção de tais conceitos.

\section{Ética, moral e educação}

Vemos, constantemente, referências ao conceito de ética, sobretudo nas ciências humanas (ou mesmo biológicas, quando se está falando a respeito da vida etc.). Percebe-se a utilização desse conceito quase como sinônimo de posturas necessárias diante de algum fenômeno humano. Tais posturas costumam ser definidas por entidades de classe - sindicatos, por exemplo - e aplicadas dentro de toda essa facção: um código de ética.

De acordo com sua definição vernácula, temos ética como o "estudo dos juízos de apreciação referentes à conduta humana suscetível de qualificação do ponto de vista do bem e do mal, seja relativamente a determinada sociedade, seja de modo absoluto." (FERREIRA; Aurélio. B.H. Dicionário básico da Lingua Portuguesa. Rio de Janeiro: Nova Fronteira, 1986).

A moral, por sua vez, não tem a preferência de todos para ser citada. Em geral, quando acontece, trata-se de "qualidades de caráter" ou como qualidade da pessoa "moralista", que impõe sua moral, seus valores. Novamente consultando o vernáculo, temos:
"Moral [do latim morale: relativo aos costumes]. (...) 1- Conjunto de regras de conduta consideradas como válidas, quer de modo absoluto para qualquer tempo ou lugar, quer para grupo ou pessoa determinada.

2. Conclusão moral que se tira de uma obra, um fato etc. 3- (substantivo masculino): o conjunto de nossas faculdades morais, brio, vergonha. 4- O que há de moralidade em qualquer coisa. 5- (adjetivo): relativo à moral. 6- Que tem bons costumes. 7- relativo ao domínio espiritual (em oposição ao físico material).” (FERREIRA, Op.cit.)

É notável que, quando nos utilizamos do conceito de ética como referência a uma postura, um modo de agir "correto", estamos, ao menos no que se refere às definições encontradas no dicionário, reduzindo a ética ao domínio da moral. A moral é a regra, o que é instituído, os modelos, os valores. A moral é algo do domínio das normas. A ética, por sua vez, é o processo. Ela se refere aos valores, é certo, mas não enquanto algo pronto, terminado: é o estudo das normas, a reflexão sobre os valores visando instituir regras para o bem comum. Regras essas que, uma vez instituídas, passam a ser expressão da moral.

Não encontramos, portanto, nada de degradante nessa idéia de moral, seja em si mesma, seja quando a comparamos à definição de ética.

Retomaremos mais adiante tais tópicos que são, ao nosso entender, condição sine qua non para se pensar qualquer fenômeno educativo.

\section{A produção da realidade: pensando as inter-relações humanas na escola}

Reconhecemos que vivemos em uma sociedade a partir de regras definidas (morais) que nos indicam os modelos considerados adequados ou desejáveis de comportamento, independente de alguns desses valores serem passíveis de crítica. Como podemos pensar a construção 
da realidade e, conseqüentemente, a construção de tais valores? É sobre esse assunto que pretendemos discutir brevemente neste momento.

Utilizaremos, como instrumento para tal análise, a leitura que DELEUZE (1981) faz de outro filósofo igualmente conhecido, qual seja, SPINOZA.

De acordo com este último, toda a realidade é resultante do encontro entre o que ele chama de corpos. Corpo não é simplesmente um aparato biológico, mas tudo aquilo que, em um encontro, tem o poder de afetar outro corpo e ser afetado por ele.

Nossa realidade escolar, por exemplo, não é apenas construída pelos professores, alunos, funcionários da escola e população circunvizinha, mas também pelo prédio escolar, pelo material didático, pelos juízos que cada pessoa tem da vida, pelas leis e programas autoritariamente baixados por decreto pelo Estado (que, em si, também é um corpo) etc.

"No encontro, os corpos em seu poder de afetar e serem afetados, se atraem ou se repelem. Dos movimentos de atração e repulsa geram efeitos: os corpos são tomados por uma mistura de afetos. Eróticos, sentimentais, estéticos, perceptivos, cognitivos..." (ROLNIK, 1987:25).

Essa concepção de produção social da realidade nos indica algumas conseqüências interessantes. Primeiramente, se consideramos que o real se produz a partir do encontro entre corpos, é a própria vida que se produz nos encontros. Em segundo lugar, o que viabiliza a vida não estaria propriamente dentro dos corpos, mas fora, mais precisamente "entre": é o espaço que possibilita que os corpos se encontrem. Finalmente, o resultado do encontro entre corpos vai ser conseqüência direta dos afetos que eles venham a trocar, ao se afetarem mutuamente, atualizando-se. (Cf. MENIN, 1996).

Dessas conseqüências, as idéias spinozistas nos levam a repensar a ética e a moral, na medida em que o encontro entre corpos produz efeitos imprevisíveis.
Não há, sob essa perspectiva, modelos preestabelecidos que possam servir como universais. Não há o bem e o mal, mas o bom e o ruim; o que é bom para um corpo pode não ser para outro. No encontro, definir-se-ão os valores, as regras, o que pode e o que não pode.

\section{Conhecimento e ética}

Se considerarmos os pressupostos teóricos propostos como instrumentos para a visualização da produção da paisagem institucional escolar, encontraremos situações bastante delicadas: vimos que não existem regras preestabelecidas para o encontro, visto que os corpos são diferentes, funcionando a partir de normas, modelos e valores (domínios da moral) diferentes, e que a ética é exatamente o processo de construção de tais valores.

É claro que existem os valores ditos "socialmente aceitos" e impostos socialmente. Essa imposição, porém, não significa que tais valores são simplesmente assumidos de maneira cega. A escola é um local privilegiado para a percepção desse fenômeno.

Por exemplo, em uma determinada sala de aula da escola em que desenvolvemos o trabalho, encontramos, certa vez, um professor que nos pareceu comprometido com seus alunos e consciente de sua ação política e seu importante papel de transformação social, pelo simples fato de ensinar algo para além do senso comum. Levado por esses valores, ele tentava trabalhar sua disciplina em uma sala com quarenta alunos, dez dos quais cuidadosamente instalados no "fundão" da sala, adeptos do rap, do hip-hop, do grafite ou, em uma hipótese ruim, das drogas pesadas.

Enquanto o professor tentava capacitar o aluno com o conhecimento, visto que, segundo GRAMSCI (1978:130), “a escola, mediante o que ensina, luta contra o folclore, contra todas as sedimentações tradicionais de concepções de mundo (...)", visando a superação das leis naturais e compreensão para a transformação das leis civis, os alunos estabeleciam o caos na sala de aula. 
Parece-nos que o professor que, em geral, encontramos nas escolas não é outro senão este que ilustramos com o nosso exemplo: um profissional muitas vezes perdido entre seus valores profissionais e alunos que, (re) citando PARO (1997), são o objeto da ação educativa. Lembramos, ainda inspirados em PARO, que o produto da escola não pode ser considerado a aula, visto que, se o trabalho humano é "uma atividade adequada a um fim" (MARX, s.d. , p.202), a aula é apenas uma atividade, o trabalho, não seu produto final, que deve ser exatamente esse aluno transformado pelo conhecimento. (Cf. PARO, 1997).

Apesar disso, o conhecimento trabalhado em sala de aula não serve na opinião desses alunos. Eles não vêem nele qualquer utilidade. Como diria SAVIANI (1980), eles não têm necessidade desse conhecimento. Pouco importa se é um valor socialmente aceito que escola é um lugar onde se deva estudar. A imposição social, nesse caso, faz pouca diferença, pois não tem eficiência em moldar o comportamento destes alunos que, de modo geral, acabam deixando a escola ou sendo expulsos dela.

Existem, a despeito disso, conhecimentos pré-concebidos envolvidos nesse encontro entre - pelo menos - alunos e professor; o conteúdo da disciplina em si, os valores do professor e os valores de cada aluno presente. Como já foi dito, no entanto, o que é bom para um corpo pode não ser para o outro. Assim sendo, não adianta, simplesmente, o professor querer que seus alunos aprendam, que sejam críticos e tenham "consciência" da realidade que os cerca.

\section{Do professor como um moralizador ao respeito às singularidades: bus- cando conclusões}

Podemos, neste momento, passar às conclusões dos constructos teóricos que fundamentam este trabalho de campo. Para tanto, faz-se necessário diferenciar a função moralizadora do métier de professor de sua ação ética.
Primeiramente, dando continuidade ao que vínhamos discutindo, o aluno vai se interessar pelo conteúdo na medida em que encontrar ligação entre este e sua vida cotidiana. Considerar a alteridade, portanto, não implica em o professor abrir mão de seus valores em prol dos valores dos alunos, muito menos impor os seus valores, mas compor eticamente valores coletivos com esses alunos. Isso implica em uma tarefa extremamente complexa que é enfrentar as vertiginosas mudanças dos territórios existenciais, enfrentando o medo de se deparar com uma realidade onde não basta seguir scripts prontos, mas onde é preciso construí-los.

Como diz o velho lema da educação popular, é preciso transformar-se para transformar. Dominar os conteúdos e estratégias é condição importante, porém não suficiente. É preciso uma postura diante do caos. E o que é a vida senão uma seqüência infinita de estados de ordem que, por não mais servirem aos encontros dos corpos, são aniquilados pelo caos (domínio da ética), para daí engendrarem outra ordem (domínio da moral) até estes territórios não mais servirem e serem novamente desintegrados, e assim por diante... (Cf. ROLNIK, 1994).

$\bigcirc$ professor diante do caos, simplesmente, não sabe o que fazer e, como já disse DELEUZE (1981), "basta não compreender para moralizar." O professor, então, recorre não à ética, ao processo de construção de valores que considera todos os corpos envolvidos no encontro que está a configurar a sala de aula, mas à moral, a idéias como "a escola é lugar para se estudar" ou "para estudar é preciso silêncio" etc.

Assim, pouco importa a atualidade ou qualidade dos conteúdos, se eles não agenciam uma prática. Nas palavras de GRAMSCI (1978), “a participação realmente ativa do aluno (...) só pode existir se a escola for ligada à vida” (p.133) - isto é, ousamos completar, se a escola for ligada aos encontros permanentes que estão perpetuamente a mudar as paisagens do cotidiano. Caso contrário, tal participação continuará a existir, mas de modo dissimulado e marginal, caso da 
bagunça que fazem os alunos nas aulas ou das depredações de que são vítimas as escolas. (Cf. MENIN, 1996).

Certamente, o grande problema em se ensinar a ética é que esta é processo. Só se ensina ética praticando a ética, ou seja, vivendo o respeito à diferença e à construção coletiva do real, para formar um aluno apto a ingressar em uma construção coletiva de mundo.

Esse talvez seja o grande problema em se criar mecanismos para a participação coletiva: tais mecanismos não existem a priori, devendo ser criados permanentemente.

\section{Trabalhando com os diferentes grupos na escola}

Uma vez compreendidos os pressupostos teóricos que fundamentaram nosso trabalho, é hora de entender seu desenvolvimento.

Primeiramente, com base nos conceitos de ética, moral, corpo e encontro dos pensadores Gilles Deleuze e Félix Guattari, foram analisadas por nós as diversas realidades produzidas em cada grupo de pessoas dentro da escola. Verificamos, nesse momento, os discursos destoantes de professores, alunos, direção da escola e pais (estes últimos, superficialmente trabalhados): os professores defendendo jargões do tipo "escola é para se estudar" e alunos denunciando uma suposta distância muito grande entre os conteúdos ali ensinados e a prática cotidiana que é a vida. Os demais funcionários da escola cobrando alunos idealizados, dóceis e obedientes, enquanto que os pais de alunos defendiam a necessidade dos filhos aprenderem, irem à escola para estudar, para fugir do mundo das drogas, para conseguirem um emprego melhor etc. Por fim, a diretora e a vicediretora defendiam a necessidade da participação de todos na gestão da escola, de modo democrático, mas não sabiam exatamente como se constrói tal processo.

Não foi possível, no pouco tempo que dispusemos, analisar qual a importância da influência (para não dizer pressão) dos pais sobre os fi- lhos, para que estes estudem, em contraposição ao desinteresse destes para com os conteúdos. Não chegamos, portanto, a conclusões significativas acerca da hipótese dos filhos manterem-se na escola para corresponderem às expectativas dos pais, por "respeito" a estes, estando, portanto, distantes de outras necessidades acadêmicas em relação ao estudo.

Posteriormente, após essa sondagem inicial de alguns dos principais interesses de cada grupo institucional, e considerando a necessidade da participação ativa (e não marginal) das pessoas na construção da realidade, realidade analisada como efeito do encontro entre corpos, foi definida, como estratégia, a organização de reuniões com pessoas representativas de cada grupo, incluindo alunos ditos marginalizados, para analisar as necessidades de cada um (baseadas em seus valores), buscando uma composição ética, de valores morais comuns, que permitisse o diálogo entre esses grupos. Tais reuniões tornaram mais claras as diferenças de interesses dos grupos, já mencionadas.

Por fim, representantes de todos os grupos foram reunidos, com vistas a tentarem compor valores mínimos que fossem comungados por todos, sobre os quais seriam definidos interesses comuns para o futuro da escola. Esse foi o momento mais delicado, visto que alguns professores e funcionários se negaram a ouvir as reivindicações e críticas dos alunos, ficando, a princípio, fora do processo, sendo reintegrados mais tarde. A presença de pais nestas reuniões foi mínima, quase inexistente, estando seus representantes informados do andamento dos acontecimentos por meio do Conselho de Escola periodicamente realizado (aproximadamente a cada 40 dias).

Instituiu-se, então, um código de ética básico, de caráter mutável e dinâmico, a partir do qual se fazia possível o diálogo entre os diferentes grupos institucionais e onde seus interesses, por vezes conflitantes, podiam ser cotidianamente discutidos. Os conflitos foram muitos, mas colocados de modo claro, como problemas comuns que precisavam ser resolvidos. 
Houve, ainda, constantes mudanças, como saída e entrada de novos professores e alunos na escola, que geravam a permanente revisão dos acordos fundados pelos diferentes grupos, demonstrando uma característica processual da ética: diferentemente da moral que constitui os valores em si, a ética mostrou-se o próprio processo de construção dos valores.

Finalmente, contatou-se que ocorreu, nos seis meses de realização do trabalho, sensível redução dos problemas de depredação e violência, dado observado por todos os grupos. Com a saída da direção e de alguns professores identificados com os ideais deste trabalho, houve um profundo retrocesso, visto que, em seis meses, não houve tempo hábil para solidificar as bases democráticas do trabalho, sobretudo entre os alunos que, segundo nossas hipóteses, receberam as melhorias como dádivas, não como uma luta que precisava ser mantida.

Dessas observações, foi possível concluir que, por meio da construção ética da realidade, considerada aqui, em síntese, como respeito aos valores de outros grupos (o respeito à diferença), uma gestão democrática apresenta-se como o caminho mais adequado para a administração dos problemas do cotidiano escolar, visto que todas as pessoas envolvidas são, de alguma forma, partícipes da construção desse cotidiano.

\section{REFERÊNCIAS BIBLIOGRÁFICAS}

BOBBIO, Norberto. O futuro da democracia : uma defesa das regras do jogo. Rio de Janeiro : Paz e Terra, 1986.

CAMPOS, Maria. M. M. As lutas sociais e a educação. Cadernos de Pesquisa, São Paulo, v. 79, p.36-64, nov. 1991. . Cidade e educação : repensando as relações entre escola e território. In: SEMINÁRIO INTERNACIONAL "CIDADE

E EDUCAÇÃO, 1994. Rio de Janeiro, 1994. (mimeogr.).

DELEUZE, Gilles. Spinoza : philosofie pratique. Paris : Minuit, 1981 , GUATTARI, Félix. Capitalisme et schizophrénie : mille plateaux. Paris : Minuit, 1980. Mil platôs : capitalismo e esquizofrenia. Rio de Janeiro : Ed. 34, 1995a. v.1. PARNET, Claire. Dialogues. Paris : Flammarion, 1977.

GRAMSCI, Antonio. Os intelectuais e a organização da cultura. Rio de Janeiro : Civilização Brasileira, 1978.

LA BOTERF, Guy de. A participação das comunidades na administração da educação. Revista de administração pública, Rio de Janeiro, v. 16, n.1, jan./mar. 1982.

MARX, Karl. O capital. Rio de Janeiro : Civilização Brasileira, [19--]. v.1.

MENIN, Pedro Augusto Hercks. Gestão e autonomia da escola: contribuições a partir de uma leitura micropolítica. São Paulo, 1996. Dissertação (Mestrado em Educação: História e Filosofia da Educação ) - Faculdade de Educação da PUC-SP, 1996.

PARO, Vitor Henrique. Administração escolar e qualidade do ensino: o que os pais ou responsáveis têm a ver com isso? In: SIMPÓSIO BRASILEIRO DE POLÍTICA E ADMINISTRAÇÃO DA EDUCAÇÃO, 18, 1997, Porto Alegre. Anais: si temas e instituições: repensando a teoria na prática. ANPAE, 1997. v.1, p.303-314.

. Gestão da escola pública : a participação da comunidade. Revista Brasileira de Estudos Pedagógicos, Brasília, v.73, n.174, 1992a.

. Participação da comunidade na gestão democrática da escola pública. Idéias, São Paulo, v.12, 1992b.

Por dentro da escola pública. São Paulo : Xamã, 1995.

PELBART, Peter Pál Ecologia do invisível. Boletim de Novidades da Livraria Pulsional, São Paulo, 1992.

PIMENTA, Selma G. Questões sobre a organização do trabalho na escola. Idéias, São Paulo, v.16, 1993.

RIVAS, Ricardo H. Política de descentralización en la educación basica y media en America Latina : estado del arte. Santiago :

Unesco/Reduc, 1991.

ROLNIK, Suely. B. Cartografia sentimental da América : produção de desejo na era da cultura industrial. São Paulo, 1987. Tese

(Doutorado) - PUC-SP, 1987.

. Cidadania e alteridade : o psicólogo, o homem da ética e a reinvenção da democracia. In: SPINK, Mary J. P. A cida-

dania em construção : uma reflexão transdisciplinar. São Paulo : Cortez, 1994. p.157-176.

SEVERINO, Antônio J.' O diretor e o cotidiano da escola. Idéias, São Paulo, v. 12, 1992. 